\title{
Частное учреждение
}

образояательная организация высшего образования «Медицинский ушиверситет «Реавиз"

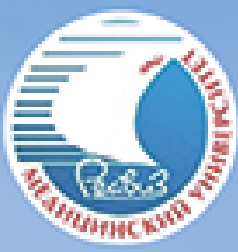

\section{С ТОМАТОЛОГИЧЕСКАЯ АЗБУКА БЕРЕМЕННОЙ}

Составители Т. А. Петрушанко, Л. И. Островская, П. Н. Большакова

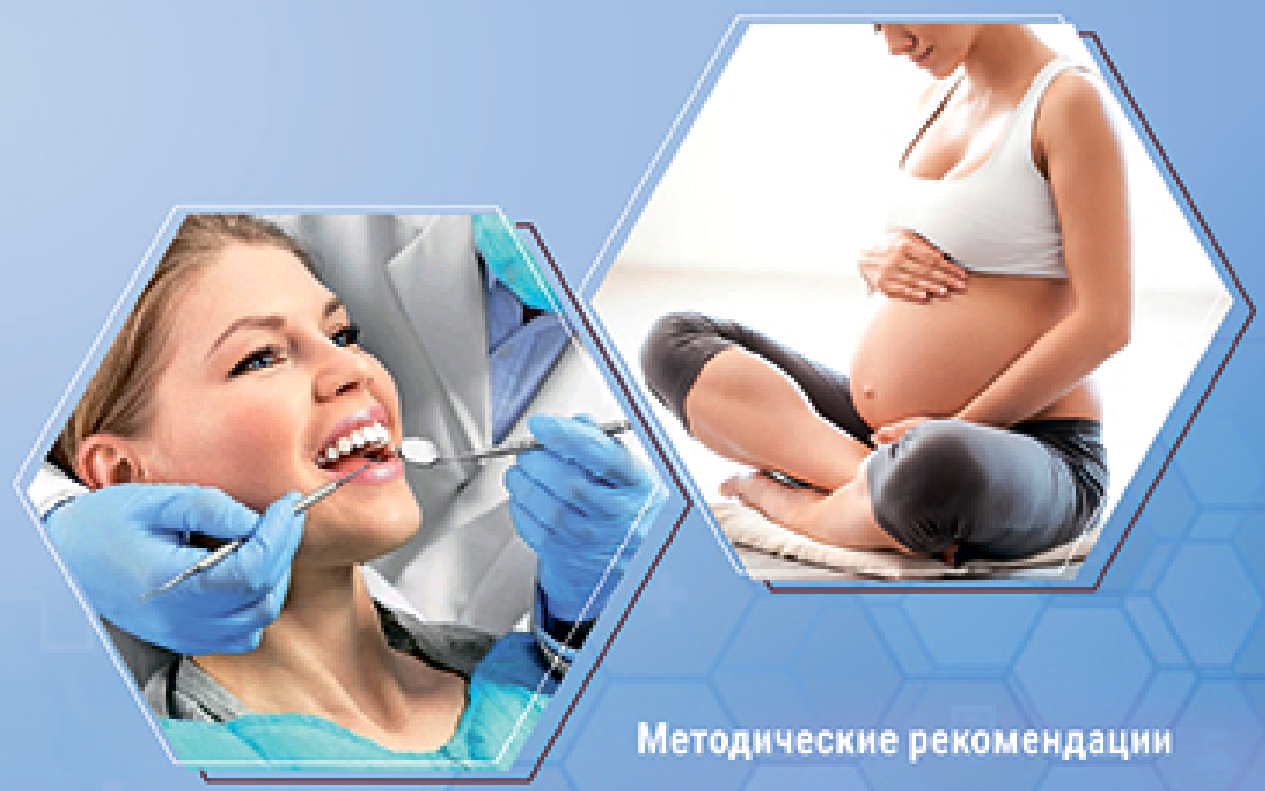


Частное учреждение

образовательная организация высшего образования «Медицинский университет «Реавиз»

\section{СТОМАТОЛОГИЧЕСКАЯ АЗБУКА БЕРЕМЕННОЙ}

Методические рекомендации для беременных, врачейстоматологов, акушеров-гинекологов, терапевтов, врачей общей практики и семейных врачей, организаторов здравоохранения

Составители

Т.А. Петрушанко, Л.И. Островская, П.Н. Большакова

Чебоксары

Издательский дом «Среда»

2021 
ББК 56.6

C81

Методические рекомендации рекомендованы

Методическим советом ЧУОО ВО «Медицинский институт «Реавиз» (протокол № 12 от 18.12.2020 г.)

\section{Рецензенты:}

Бахтияров К.Р. - д-р мед. наук, профессор кафедры акушерства, гинекологии и перинатологии ФГБОУ ВО «Первый Московский государственный медицинский университет им. И.М. Сеченова» Минздрава России (Сеченовский университет);

Мирчук Б.Н. - д-р мед. наук, профессор, декан стоматологического факультета, заведующий кафедрой ортодонтии Одесского национального медицинского университета.

С81 Стоматологическая азбука беременной : методические рекомендации для беременных, врачей-стоматологов, акушеров-гинекологов, терапевтов, врачей общей практики и семейных врачей, организаторов здравоохранения / сост. Т.А. Петрушанко, Л.И. Островская, П.Н. Большакова. Чебоксары: ИД «Среда», 2021. - 24 с.

\section{ISBN 978-5-907411-10-4}

Методические рекомендации посвящены индивидуальной профилактике стоматологических заболеваний беременной и будущего ребенка путем оптимизации рациона питания, образа жизни, рекомендаций по гигиене полости рта. Такая врачебная тактика позволяет существенно снизить распространенность и интенсивность заболеваний полости рта у беременных, рожениц, новорожденных и детей ранних лет жизни.

Методические рекомендации предназначены для беременных, врачей-стоматологов, акушеров-гинекологов, терапевтов, врачей общей практики и семейных врачей, организаторов здравоохранения.

DOI $10.31483 / \mathrm{a}-10257$

ISBN 978-5-907411-10-4
(C) Петрушанко Т.А., Островская Л.И., Большакова П.Н., составление, 2021

(C) ЧУОО ВО «Медицинский институт «Реавиз», 2021

( С ИД «Среда», оформление, 2021 


\section{О составителях}

Петрушанко Т.А. - д-р мед. наук, профессор, заведующая кафедрой терапевтической стоматологии Украинской медицинской стоматологической академии, г. Полтава;

Островская Л.И. - канд. мед. наук, доцент кафедры терапевтической стоматологии Украинской медицинской стоматологической академии, г. Полтава;

Большакова П.Н. - канд. мед. наук, доцент кафедры акушерства и гинекологии «Медицинский университет «Реавиз», г. Москва. 


\section{ВЫ БЕРЕМЕННЫ! \\ ПРИМИТЕ НАШИ ИСКРЕННИЕ ПОЗДРАВЛЕНИЯ!!! \\ Дорогая будущая мама, приветствуем Вас!}

Беременность - это ожидание новой жизни. Наша главная цель - постоянная забота о Вашем здоровье, от которого зависит здоровье ребенка. В период беременности чрезвычайно важно постоянное общение со стоматологом, который посоветует Вам, как восстановить и сохранить стоматологическое здоровье, предотвратить большинство болезней зубов, тканей пародонта, зубочелюстных деформаций у Вашего будущего малыша. Профилактика стоматологических заболеваний ребенка является эффективной именно в период беременности мамы, еще лучше - не менее чем за три месяца до наступления беременности.

Использование нашей «Азбуки» сделает Ваше общение со стоматологом приятным, информированным и результативным, состояние Вашей полости рта и ожидаемого Вами ребенка идеальным.

Это так прекрасно, когда в тебе растет новая жнинь!

С наилучшими пожеланиями Ваш доброжелательный стоматолог! 


\section{Давайте знакомиться!}

Ваши фамилия, имя, отчество

Дата рождения

Беременность - это партнерские отношения между Вами, будущим папой (родственниками или человеком, поддерживающим $\mathrm{Bac)}$ и теми людьми, которые на протяжении беременности заботятся о Вашем здоровье и здоровье Вашего ребеночка.

В ожидании малыша, пожалуйста, помните, что Ваш врачстоматолог заинтересован в том, чтобы сделать Ваш визит в клинику комфортным и приятным. Старайтесь строить доверительные отношения с ним и соблюдать все его рекомендации.

Спрашивайте - получите ответ! Нет «бессмысленных» или ненужных вопросов, если ответ на них важен для Вас!

Оптимальная кратность посещения стоматолога беременной для эффективной профилактики стоматологических заболеваний:

- до 20 недель беременности - 1 раз в месяц;

- в сроки 20-32 недели беременности - 2 раза в месяц;

- после 32-й недели беременности - 3-4 раза в месяц.

Количество и время Ваших общений с доброжелательным стоматологом будут индивидуально определены и указаны в «Азбуке». 


\section{А ЗНАЕТЕ ЛИ ВЫ?}

Уже на 4-5 неделе беременности формируются челюстные кости плода и мягкие ткани лица.

Уже на 6-10 неделе беременности образуются зачатки всех временных зубов.

Снижение потребления сахара между 12 и 18 неделями беременности является профилактикой заболеваний полости рта плода.

Уже на 17-18 неделе беременности начинается закладка зачатков постоянных зубов. Их минерализация происходит с 20-й недели беременности (32-34 неделя - первых постоянных моляров, 38 первых постоянных резцов), окончательное созревание зубов заканчивается только через несколько лет после их прорезывания.

Построение позвоночника плода начинается после 20 недель беременности.

На 28-й неделе беременности происходит минерализация зачатков временных клыков и моляров.

\section{Факторы, нарушающие внутриутробное развитие} и нормальное формирование зубочелюстного аппарата

1) наследственность;

2) хронические соматические болезни беременной (экстрагенитальная патология);

3) гестозы беременности;

4) профессиональные вредности, действие вибрации, травмы, ионизирующее излучение, гипоксия;

5) стрессовое состояние;

6) стоматологические болезни беременной;

7) вредные привычки;

8) неполноценное питание;

9) сжатие брюшной стенки тесной одеждой;

10) действие вирусной (краснуха, грипп, ветряная оспа, Коксаки, цитомегалии, СПИД), бактериальной (сифилис, туберкулез, хламидиоз, листериоз), протозойной (токсоплазмоз) инфекции;

11) применение сильнодействующих препаратов без назначения и контроля врача;

12) низкий уровень санитарно-гигиенической культуры беременной. 


\section{КАКИЕ СТОМАТОЛОГИЧЕСКИЕ ПРОБЛЕМЫ МОГУТ БЕСПОКОИТЬ БЕРЕМЕННУЮ?}

Гормональная перестройка и ряд других факторов, которые действуют во время беременности, часто приводят к возникновению или прогрессированию (если до беременности уже были изменения в тканях десен) болезней тканей пародонта. Ухудшаются показатели состояния слюны, уменьшается ее количество, что приводит к снижению качества гигиены полости рта.

В период беременности, и особенно во время лактации, возможно ухудшение состояния зубов - увеличение распространенности и тяжести кариозного процесса, выпадение пломб.

\section{Факторы, способствующие развитию стоматологических заболеваний у беременных}

1) соматическая заболеваемость (нарушение обмена веществ, хронические болезни пищеварительного тракта, хронические энтероколиты, заболевания желчевыводящих путей, почек, щитовидной железы и др.);

2) стрессорные факторы;

3) неполноценное питание;

4) наличие зубочелюстных деформаций (патология прикуса, скопления зубов), аномалий мягких тканей полости рта (короткие уздечки языка, губ, мелкое преддверие);

5) вредные привычки;

6) плохая гигиена полости рта. 


\section{ВАШ СТОМАТОЛОГИЧЕСКИЙ СТАТУС}

Дата

Дата

Дата

Дата

Дата

$87654321 \mid 12345678$

$87654321 \mid 12345678$

Дата

Дата

Дата

Дата

Дата

\section{Некариозные поражения}

I триместр

II триместр

III триместр

Состояние десен

I триместр

II триместр

III триместр

Состояние слизистой оболочки других отделов полости рта

I триместр

II триместр

III триместр

\section{Гигиена полости рта}

I триместр

II триместр

III триместр 


\section{РЕКОМЕНДАЦИИ ПО ИНДИВИДУАЛЬНОЙ ПРОФИЛАКТИКЕ СТОМАТОЛОГИЧЕСКИХ ЗАБОЛЕВАНИЙ У ВАС И БУДУЩЕГО РЕБЕНКА}

- Освободитесь от тяжелых физических нагрузок, ночных смен, командировок, работы, связанной с вибрацией, высокой температурой, магнитным полем, химическими веществами.

- Нежелательна работа в наклоненном состоянии

- Чередуйте работу с отдыхом через каждые 40-50 минут.

- При сидячей работе необходимо двигаться через каждые 2 часа.

- Желательны прогулки на свежем воздухе несколько раз в день по 1-1,5 часа, обязательна прогулка перед ночным сном.

- Ночной сон целесообразно продлить на 2 часа, 1,5-2 часа выделить на сон днем.

- Ваша одежда должна быть удобного покроя, без поясов, резинок, обувь - легкой, удобной, на широких низких каблуках. Утренняя гимнастика должна быть без переутомления, лучший вид спортивных занятий - плавание.

- Избавьтесь от вредных привычек.

- Выполняйте антистрессорную профилактику:

- «ожидание» ребенка должно быть с положительной мотивацией;

- психологический климат в семье должен быть с положительными эмоциями, вниманием, улыбками, любовью;

- чаще занимайтесь музыкотерапией, аутотренингом, самопрофилактикой стресса. 


\section{РЕКОМЕНДАЦИИ ПО ВАШЕМУ ПИТАНИЮ}

- Пища должна быть разнообразной, сбалансированной, с большим количеством сырых овощей, фруктов, ограничением употребления легкоусвояемых углеводов, особенно сахара.

- Питание должно быть полноценным по содержанию белков (100-120 г в сутки), жиров (80-100 г), углеводов (350-400 г в первой половине беременности, 300-350 г перед родами).

- Следует ограничить употребление мясных и рыбных консервов, копченых продуктов, солений, любых колбас, сосисок, готовых пельменей, куриных рулетов, рыбных и крабовых палочек, продуктов в вакуумной упаковке.

- Привычку пить кофе каждое утро следует заменить употреблением отвара шиповника или некрепкого чая с медом.

- Есть нужно небольшими порциями 5-6 раз в день. Суточная энергетическая потребность рациона в первой половине беременности - 2500-3000 ккал, во второй - в среднем 2900 ккал.

- Допустимое увеличение массы тела во время беременности 9,0-13,6 кг. Если до 20 недель прибавка в массе тела менее 4,5 кг рацион питания следует пересмотреть.

\section{Примерный суточный рацион беременной в первой половине беременности}

- 100 г. мяса (1-2 котлеты, 2-3 фрикадельки);

- 100 г. рыбных продуктов;

-1 яйцо;

- 2 стакана молока, 200 г сыра;

- 20 г. сметаны (1/3 стакана);

- 20 г. (2 ч.л.) масла, 25 г сливочного масла;

- 500 г. овощей (по 100 г капусты, свеклы, моркови, 200 г томатов), 35 г. лука (зеленого, репчатого), 150-200 г. картофеля;

- 300-400 г фруктов;

- по 150 г. хлеба ржаного и пшеничного (3-4 кусочка);

- 60 г. круп и макаронных изделий;

- не более 60 г. сахара и кондитерских изделий.

Изменения в ориентированном суточном рационе беременной во второй половине беременности

- увеличение до 150 г. мяса (нежирные сорта, отварное);

- увеличение до 120 г. рыбных продуктов;

- 3 стакана молока, 1 стакан кефира;

- 30 г (3 ч. л.) масла, 15 г. сливочного масла;

-500 г фруктов. 
В поступлении в организм витаминов и макро- и микроэлементов следует отдать предпочтение пищевым продуктам.

Таблица 1

Рекомендуемые нормы потребления витаминов для беременных и женщин в период лактации

\begin{tabular}{|c|c|c|}
\hline $\begin{array}{l}\text { Название } \\
\text { витамина }\end{array}$ & $\begin{array}{l}\text { Суточная } \\
\text { потребность } \\
\text { (мГ / сут) }\end{array}$ & Источники поступления \\
\hline $\begin{array}{c}\text { С } \\
\text { (Аскорбиновая } \\
\text { кислота) }\end{array}$ & $90-120$ & $\begin{array}{l}\text { черная смородина, черноплодная рябина, } \\
\text { шиповник, цитрусовые, брокколи, } \\
\text { сладкий }\end{array}$ \\
\hline $\begin{array}{c}\text { А } \\
\text { (Ретинол) }\end{array}$ & $1,0-1,4$ & $\begin{array}{l}\text { рыбий жир, печень, яичный желток, } \\
\text { сметана, сливочное масло, красно- } \\
\text { оранжевые овощи, зелень }\end{array}$ \\
\hline $\begin{array}{c}\mathrm{D} \\
\text { (Кальциферол) }\end{array}$ & 10 мкг & $\begin{array}{l}\text { желток яиц, печень, рыбий жир, } \\
\text { сливочное масло, сыр, молоко }\end{array}$ \\
\hline $\begin{array}{c}\mathrm{E} \\
\text { (Токоферол) }\end{array}$ & $10-14$ & $\begin{array}{l}\text { растительные жиры, зародыши злаковых, } \\
\text { бобовые, яйца, морская рыба, шпинат, } \\
\text { кресс-салат }\end{array}$ \\
\hline $\begin{array}{c}\mathrm{B} 1 \\
\text { (Тиамин) } \\
\end{array}$ & $1,5-2,1$ & $\begin{array}{l}\text { свинина, овсяная, гречневая крупы, } \\
\text { печень, черный хлеб, яйца }\end{array}$ \\
\hline $\begin{array}{c}\text { B2 } \\
\text { (Рибофлавин) }\end{array}$ & $1,6-2,3$ & $\begin{array}{l}\text { яйца, сыр, молоко, гречневая крупа, } \\
\text { печень, мясо }\end{array}$ \\
\hline $\begin{array}{c}\text { B6 } \\
\text { (Пиридоксин) }\end{array}$ & $2,1-2,3$ & $\begin{array}{l}\text { печень, почки, мясо, ячменная крупа, } \\
\text { кукурузная, соя }\end{array}$ \\
\hline $\begin{array}{c}\text { РP } \\
\text { (Ниацин) }\end{array}$ & $16-25$ & $\begin{array}{l}\text { печень, мясо, рыба (более всего } \\
\text { в лососевых видах), бобовые, гречневая } \\
\text { крупа, черный хлеб }\end{array}$ \\
\hline $\begin{array}{c}\mathrm{B} 12 \\
\text { (Кобаламин) } \\
\end{array}$ & 4 мкГ & печень, почки, рыба, мясо \\
\hline $\begin{array}{c}\text { K } \\
\text { (Нафтохинон) }\end{array}$ & 75-90 мкг & $\begin{array}{l}\text { шпинат, помидоры, земляника, цветная } \\
\text { капуста, свиная печень, свинина, } \\
\text { говядина, крапива }\end{array}$ \\
\hline $\begin{array}{c}\mathrm{Bc} \\
\text { (Фолиевая } \\
\text { кислота) }\end{array}$ & 400 мкг & $\begin{array}{l}\text { бобовые, арахис, хлеб, шпинат, петрушка, } \\
\text { спаржа, брокколи, брюссельская капуста, } \\
\text { дрожжи, печень, почки, мясо }\end{array}$ \\
\hline $\begin{array}{c}\mathrm{B} 3 \\
\text { (Пантотеновая } \\
\text { кислота) }\end{array}$ & 5 & $\begin{array}{l}\text { пчелиное маточное молоко, печень, яйца, } \\
\text { рыба, хлеб }\end{array}$ \\
\hline $\begin{array}{c}\mathrm{H} \\
\text { (Биотин) }\end{array}$ & $\begin{array}{c}\text { беременные - } \\
30 \text { мкг в период } \\
\text { лактации - } 35 \text { мкг }\end{array}$ & $\begin{array}{l}\text { печень, соя, желтки яиц, цветная капуста, } \\
\text { рис, дрожжи, шоколад, арахис }\end{array}$ \\
\hline
\end{tabular}


Таблица 2

Рекомендуемые нормы потребления макро- и микроэлементов для беременных и женщин в период лактации

\begin{tabular}{|c|c|c|}
\hline $\begin{array}{c}\text { Название } \\
\text { макро- или } \\
\text { микроэлемента } \\
\end{array}$ & $\begin{array}{c}\text { Суточная потребность } \\
\text { (мг / сут) }\end{array}$ & Источники поступления \\
\hline Кальций & $\begin{array}{l}\text { беременные - } 1100 \\
\text { период лактации - } 1200\end{array}$ & $\begin{array}{l}\text { молоко, сыр, йогурт, рыба, } \\
\text { капуста, } \\
\text { картофель, абрикосы, свекла, соя }\end{array}$ \\
\hline Фосфор & $\begin{array}{l}\text { беременные - } 1650 \\
\text { период лактации - } 1800\end{array}$ & $\begin{array}{l}\text { молочные продукты, рыба, } \\
\text { крыжовник, яблоки, абрикосы, } \\
\text { персики, вишня, слива, свекла, соя }\end{array}$ \\
\hline Магний & 450 & сыр, крупяные каши \\
\hline Железо & $\begin{array}{l}\text { беременные - } 38 \\
\text { период лактации - } 33\end{array}$ & $\begin{array}{l}\text { печень, почки, яйца, мясо, овсяная, } \\
\text { крупа, персики, гранаты, яблоки, } \\
\text { черная смородина, } \\
\text { сухофрукты,шпинат, курага }\end{array}$ \\
\hline Цинк & $\begin{array}{l}\text { беременные - } 20 \\
\text { период лактации - } 25\end{array}$ & $\begin{array}{l}\text { твердые сыры, мясо кролика, } \\
\text { зеленый горох, капуста, морковь, } \\
\text { груши, апельсины }\end{array}$ \\
\hline Медь & $\begin{array}{l}\text { беременные }-1,0 \\
\text { период лактации }-1,3\end{array}$ & печень, мясо, рыба, бобовые \\
\hline Йод & $2,1-2,3$ & $\begin{array}{l}\text { рыбий жир, йодированная соль, } \\
\text { морские водоросли, моллюски }\end{array}$ \\
\hline Селен & $\begin{array}{l}\text { беременные }-60 \text { мкг } \\
\text { период лактации - } 70 \text { мкг }\end{array}$ & морепродукты, чеснок \\
\hline Хром & $\begin{array}{l}\text { беременные - } 30 \text { мкг } \\
\text { период лактации - } 45 \text { мкг }\end{array}$ & печень \\
\hline
\end{tabular}


Индивидуальные рекомендации стоматолога по питанию

Индивидуальные рекомендации

и медикаментозные назначения стоматолога 


\section{РЕКОМЕНДАЦИИ ПО ГИГИЕНЕ ПОЛОСТИ РТА}

Ваша индивидуальная гигиена полости рта - чрезвычайно важная и фундаментальная процедура, которая позволяет не только сохранить и улучшить состояние зубов, тканей пародонта, общее самочувствие, но и предотвратить ряд осложнений во время родов и главное - избежать болезней и патологических состояний у будущего малыша.

Необходимые для Вас средства индивидуальной гигиены полости рта

Зубная щетка

Малопучковая зубная щетка

Средства интердентальной гигиены:

- Межзубные ершики

- Флоссы

- Специальные зубочистки

- Суперфлоссы

- Флосеты

Зубные пасты для чистки зубов

Зубные пасты для массажа десен

Ирригатор

Массажное устройство

Средства по уходу за языком 
Жидкие средства гигиены для полости рта

Жевательная резинка

Индикаторные средства для контроля гигиены

1. Ополаскивание полости рта $1 / 2$ стакана воды.

2. Чистка межзубных промежутков.

3. Чистка языка.

4. Ополаскивание водой или рекомендованными ополаскивателями.

5. Чистка зубов.

6. Споласкивание зубной пасты водой разной температуры (термозакаливание сосудов десен и полости рта) $-34-35^{\circ}$ и $19-24^{\circ} \mathrm{C}$ поочередно, завершая водой низкой температуры. Следует интенсивно прополоскать водой преддверие полости рта в течение 3 c, а дальше - собственно полость рта (10-15 с).

7. Массаж десен (пальцевой с втиранием зубной пасты, массажное устройство).

8. Термозакаливание сосудов десен и полости рта.

9. Орошения ирригатором или ротовые ванночки ополаскивателем или бальзамом.

\section{После еды в течение дня}

1. Ополаскивания полости рта $1 / 2$ стакана воды.

2. Чистка межзубных промежутков.

3. Применение жевательной резинки не более 10 мин.

\section{После ужина}

1. Ополаскивания полости рта $1 / 2$ стакана воды.

2. Чистка межзубных промежутков.

3. Ополаскивания водой или рекомендованным ополаскивателем.

4. Чистка зубов.

5. Споласкивания зубной пасты водой разной температуры (термозакаливание сосудов десен и полости рта) $-34-35^{\circ}$ и $19-24^{\circ} \mathrm{C}$ поочередно, завершая водой низкой температуры.

6. Орошения или ротовые ванночки ополаскивателем или бальзамом. 
Изменения в алгоритме индивидуальной гигиены полости рта

Медикаментозные назначения

для местной терапии или профилактики 


\section{ПОМНИТЕ!}

\section{У счастливых родителей рождаются счастливые дети!}

Полноценное счастье возможно только у здорового человека. Ваше здоровье в полной мере определяется Вашим отношением к себе, к тем рекомендациям и назначениям, которые предлагают Вам семейный врач, акушер-гинеколог, стоматолог, педиатр и другие специалисты. Они заботятся о здоровье непосредственно Вашем и будущего ребенка. В Ваших силах подарить малышу красоту и здоровье.

Период лактации не менее значим и ответственен как для общего, так и стоматологического здоровья мамы и малыша. Поэтому не пренебрегайте советами и назначениями врачей, в том числе и стоматолога, в послеродовой период.

Лучшая профилактика стоматологических заболеваний у ребенка - кормление грудью. Однако кормление грудью более года, особенно «по требованию», не избавляет от кариеса, а ведет к развитию кариеса верхних резцов. Следует соблюдать требования к полноценному питанию женщины в период лактации и правила естественного, а при необходимости - искусственного кормления детей. Родители должны ограничить углеводсодержащие и кислые напитки и продукты, вызывающие брожение сахаров. Молоко, каши, кефир, подслащенные чай, компот и др., которые даются малышу ночью и в промежутках между основными приемами пищи, обладают кариесогенным воздействием.

В возрасте 12 месяцев бутылка должна быть заменена на чашку, необходимо избегать постоянного использования пустышки во время засыпания и ночью.

С целью профилактики раннего детского кариеса (бутылочного кариеса), зубочелюстных деформаций, правильного формирования тканей пародонта и прорезывания зубов в возрасте до 6 месяцев ребенка необходимо показать детскому стоматологу. Ранний детский кариес имеет инфекционную природу и не обнаруживается у детей до тех пор, пока не прорежутся зубы. Инфекция в полость рта ребенка попадает со слюной взрослых при облизывании сосок, ложек, поцелуях.

Наиболее эффективным методом предупреждения развития кариеса являются начало гигиенического ухода и соблюдение рекомендаций стоматолога с момента прорезывания первых зубов, 
когда ребенка необходимо приучать к ежедневной двукратной их чистке. Вначале следует протирать десны младенцев марлевыми или ватными тампонами или специальными резиновыми щеточками - «напальчниками». Уже с 2-летнего возраста важно обучать ребенка самостоятельной чистке зубов. Зубные пасты рекомендуется применять с 3-х лет, когда ребенок уже научился полоскать рот.

Таблица 3

РЕЖИМ ДНЯ РЕБЕНКА ПЕРВОГО ГОДА ЖИЗНИ

\begin{tabular}{|c|c|c|c|c|c|c|c|}
\hline & \multicolumn{3}{|c|}{ Кормление } & Бодрствование & \multicolumn{3}{c|}{ Сон } \\
\hline $\begin{array}{c}\text { Возраст } \\
\text { в мес. }\end{array}$ & Кол-во & $\begin{array}{c}\text { Интервал } \\
\text { в часах }\end{array}$ & $\begin{array}{c}\text { Ночной } \\
\text { перерыв } \\
\text { в часах }\end{array}$ & $\begin{array}{c}\text { Максимальная } \\
\text { длительность } \\
\text { в часах }\end{array}$ & Кол-во & $\begin{array}{c}\text { Длитель- } \\
\text { ность } \\
\text { каждого } \\
\text { сна } \\
\text { часах }\end{array}$ & $\begin{array}{c}\text { Всего } \\
\text { часов }\end{array}$ \\
\hline $0-3$ & $6-7$ & $3-3,5$ & $6-6,5$ & $1-1,5$ & 4 & $1,5-2$ & $\begin{array}{c}17,8- \\
18,5\end{array}$ \\
\hline $3-6$ & $5-6$ & $3,5-4$ & $6,5-8$ & $1-1,5$ & 4 & $1,5-2$ & $\begin{array}{c}16,5- \\
17,5\end{array}$ \\
\hline $6-9$ & 5 & 4 & $8 *$ & $2-2,5$ & 3 & $1,5-2$ & $\begin{array}{c}15- \\
16,5\end{array}$ \\
\hline $9-12$ & $4-5$ & $3,5-4$ & $8 * *$ & $2,5-3$ & 2 & до 1,5-2 & $\begin{array}{c}14,5- \\
15,5\end{array}$ \\
\hline
\end{tabular}

* при 11 часах сна

**при 10-11 часах сна 
Таблица 4

ОСНОВНЫЕ ПОКАЗАТЕЛИ ФИЗИЧЕСКОГО РАЗВИТИЯ

\begin{tabular}{|c|c|c|c|c|c|c|}
\hline $\begin{array}{c}\text { Возраст в } \\
\text { месяцах }\end{array}$ & Вес, г & $\begin{array}{c}\text { Месячная } \\
\text { прибавка } \\
\text { веса, г }\end{array}$ & $\begin{array}{c}\text { Рост } \\
\text { в см }\end{array}$ & $\begin{array}{c}\text { Месячная } \\
\text { прибавка } \\
\text { роста, см }\end{array}$ & $\begin{array}{c}\text { Окружность } \\
\text { головы, см }\end{array}$ & $\begin{array}{c}\text { Окружность } \\
\text { груди, см }\end{array}$ \\
\hline Рождение & $\begin{array}{c}3100- \\
3500^{*}\end{array}$ & & $\begin{array}{c}50- \\
51\end{array}$ & & $34-35$ & $32-34$ \\
\hline 1 & $\begin{array}{c}3700- \\
4100\end{array}$ & 600 & $\begin{array}{c}54- \\
55\end{array}$ & 3 & $36-37$ & $35-36$ \\
\hline 2 & $\begin{array}{c}4500- \\
4900\end{array}$ & 800 & $\begin{array}{c}55- \\
59\end{array}$ & 3 & $38-39$ & $37-38$ \\
\hline 3 & $\begin{array}{c}5200- \\
5600\end{array}$ & 800 & $\begin{array}{c}60- \\
62\end{array}$ & 2,5 & $40-41$ & $39-40$ \\
\hline 4 & $\begin{array}{c}5900- \\
6300\end{array}$ & 750 & $\begin{array}{c}62- \\
65\end{array}$ & 2,5 & $41-42$ & $41-42$ \\
\hline 5 & $\begin{array}{c}6500- \\
6800\end{array}$ & 70 & $\begin{array}{c}64- \\
68\end{array}$ & 2 & $42-43$ & $43-44$ \\
\hline 6 & $\begin{array}{c}7100- \\
7400\end{array}$ & 650 & $\begin{array}{c}66- \\
70\end{array}$ & 2 & $43-44$ & $45-46$ \\
\hline 7 & $\begin{array}{c}7600- \\
8100\end{array}$ & 600 & $\begin{array}{c}68- \\
72\end{array}$ & 2 & $43,5-44,5$ & $45,5-46,5$ \\
\hline 8 & $\begin{array}{c}5100- \\
8500\end{array}$ & 550 & $\begin{array}{c}69- \\
74\end{array}$ & 2 & $44-45$ & $46-47$ \\
\hline 9 & $\begin{array}{c}8600- \\
9000\end{array}$ & 50 & $\begin{array}{c}70- \\
75\end{array}$ & 1,5 & $44,5-45,5$ & $46,5-47,5$ \\
\hline 10 & $\begin{array}{c}9100- \\
9500\end{array}$ & 450 & $\begin{array}{c}71- \\
76\end{array}$ & 1,5 & $45-46$ & $47-48$ \\
\hline 11 & $\begin{array}{c}9500- \\
10000\end{array}$ & 400 & $\begin{array}{c}72- \\
78\end{array}$ & 1,5 & $45,5-46,6$ & $47,5-48,5$ \\
\hline 12 & $\begin{array}{c}10000- \\
10800\end{array}$ & 350 & $\begin{array}{c}74- \\
80\end{array}$ & 1,5 & $46-47$ & $48-49$ \\
\hline
\end{tabular}

*B первые дни после рождения малыш теряет в весе и это естественный процесс. Максимальная потеря веса младенца к 3-5 дню составляет 6-8\% от массы при рождении. Отклонение от средних данных является нормой и не должно служить поводом для беспокойства! 


\section{СХЕМА ПРОРЕЗЫВАНИЯ ЗУБОВ}

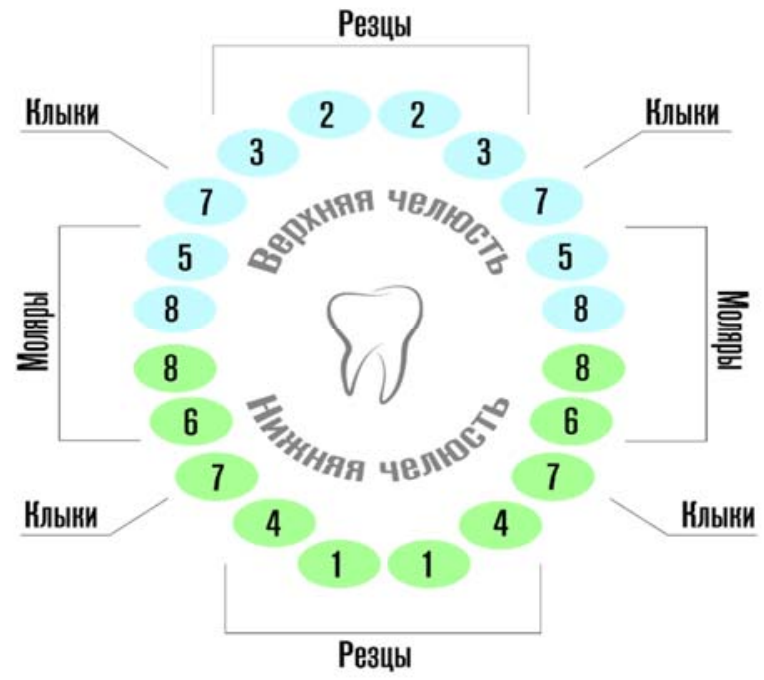

\begin{tabular}{c|c} 
Зубы в порядке появления & Средний срок \\
появления
\end{tabular}

1 Нижние центральные резцы 6-7 мес

2 Верхние центральные резцы 8-9 мес.

3 Верхние боковые резцы 9-11 мес.

4 Нижние боковые резцы 11-13 мес.

5 Верхние первые моляры $12-15 \mathrm{Mec}$.

6 Нижние первые моляры $12-15 \mathrm{Mec}$.

7 Клыки 18-20 мес.

8 Вторые моляры 20-30 мес.

\section{СЧАСТЛИВОЙ ВАМ БЕРЕМЕННОСТИ}

И ПРИЯТНОГО МАТЕРИНСТВА! 


\section{ПУСТЬ У ВАШЕГО МАЛЫША БУДУТ БРАТИК \\ ИЛИ СЕСТРИЧКА!}

Чтоб их появление было радостным, и малыши были здоровы, необходимо как можно раньше (за 3-6 месяцев до беременности) семейной паре, планирующей беременность, а также беременной пройти обследование в лаборатории, сдав кровь на диагностику:

- TORCH - инфекций;

- Токсоплазмы (Ig M, Ig G);

- Краснухи (Ig M, Ig G);

- Цитомегаловируса (Ig M, Ig G);

- Герпеса типа 1 (Ig G, Ig M);

- Герпеса типа 2 (Ig G, Ig M).

Обследование будущей мамы включает дополнительно следующие анализы:

• развернутый клинический анализ крови;

- общий анализ мочи;

- развернутый биохимический анализ крови;

- содержание общего кальция;

- определение пролактина;

- определение ТТГ;

- определение группы крови и резус-фактора;

- изучение крови на ВИЧ;

- отборочный тест на сифилис ;

- диагностика гепатита C (анті-HCV);

- диагностика гепатита B (HBsAg);

- микроскопическое и цитологическое исследование содержимого уретры, цервикального канала и влагалища.

Обследование будущего папы включает дополнительно следующие анализы:

- развернутый клинический анализ крови;

- общий анализ мочи;

- определение группы крови и резус-фактора;

- изучение крови на ВИЧ;

- отборочный тест на сифилис;

- диагностика гепатита C (анті-HCV);

- диагностика гепатита В (HBsAg);

- микроскопическое и цитологическое исследование содержимого уретры;

при необходимости изучение спермограммы. 
Для заметок 
Для заметок 
Учебное издание

\section{СТОМАТОЛОГИЧЕСКАЯ} АЗБУКА БЕРЕМЕННОЙ

Методические рекомендации для беременных, врачей-стоматологов, акушеров-гинекологов, терапевтов, врачей общей практики и семейных врачей, организаторов здравоохранения

Чебоксары, 2021 г.

Составители

Петрушанко Татьяна Алексеевна

Островская Людмила Иосифовна

Большакова Полина Николаевна

Компьютерная верстка М.Ю. Фомин

Дизайн обложки Н.В. Фирсова

Подписано в печать 12.02.2021 г.

Дата выхода издания в свет 18.02.2021 г.

Формат 60×84/16. Бумага офсетная. Печать офсетная.

Гарнитура Times. Усл. печ. л. 1,395. Заказ К-783. Тираж 500 экз.

Издательский дом «Среда»

428005, Чебоксары, Гражданская, 75, офис 12

+7 (8352) 655-731

info@phsreda.com

https://phsreda.com

Отпечатано в Студии печати «Максимум»

428005, Чебоксары, Гражданская, 75

+7 (8352) 655-047

info@maksimum21.ru

www.maksimum21.ru 